\title{
CURRÍCULO TÉCNICO INTEGRADO AO ENSINO MÉDIO: IMPLANTAÇÃO E DESENVOLVIMENTO DE PRÁTICAS NO CONTEXTO BRASILEIRO
}

\author{
Italan Carneiro Bezerra* \\ *E-mail: italancarneiro@gmail.com \\ Instituto Federal da Paraíba - IFPB / Campus João Pessoa, Brasil \\ DOI: $10.15628 /$ rbept.2020.8177
}

Artigo submetido em jan/2019 e aceito em dez/2019

\begin{abstract}
RESUMO
Utilizando como base a pesquisa bibliográfica, discutimos neste trabalho a implantação e o desenvolvimento das concepções e práticas relacionadas à Educação Profissional de Nível Técnico realizada na forma Integrada com o Ensino Médio no contexto brasileiro. Por tratarse de uma proposta relativamente recente, cujo atual formato foi instituído em 2004, e de complexos objetivos (dentre os quais destacamos a extinção da histórica dualidade estrutural da educação brasileira), os trabalhos abordados apontam grandes dificuldades para sua efetiva implantação. Evidenciou-se então a necessidade de garantir políticas voltadas ao desenvolvimento da Proposta Integrada, sendo esta uma necessidade que precisa adquirir caráter político-institucional, não podendo estar restrita a iniciativas individuais do corpo docente.
\end{abstract}

Palavras-Chave: Currículo Integrado. Formação Integrada. Ensino Médio Integrado. Politecnia. Omnilateralidade.

\section{INTEGRATED TECHNICAL CURRICULUM TO THE SECONDARY SCHOOL: IMPLEMENTATION AND DEVELOPMENT OF PRACTICES IN THE BRAZILIAN SETTING}

\begin{abstract}
This study is to discuss the implantation and the development of the conceptions and practices related to the Professional Education of Technical Level, which are provided in the Integrated Way with the Secondary School in the Brazilian setting. For this purpose, the bibliographic research was used as basis. This is a fairly recent proposal, whose current format was established in 2004, with complex objectives, among which we highlight the extinction of the historical structural duality of Brazilian education. For this reason, the discussed works point great difficulties for its effective implementation. Accordingly, there is a need to guarantee policies aimed at the development of the Integrated Proposal. This is a need that demands political-institutional nature and cannot be restricted to individual initiatives of the teaching staff.
\end{abstract}

Keywords: Integrated Curriculum. Integrated Formation. Integrated Secondary School. Polytechnic. Omnilaterality. 


\section{INTRODUÇÃO}

Neste trabalho discorremos sobre a modalidade da Educação Técnica realizada da forma Integrada ao Ensino Médio, sendo fruto de recorte da pesquisa de doutorado intitulada "Curso Técnico Integrado ao Ensino Médio em Instrumento Musical do IFPB: reflexões a partir dos perfis discente e institucional" ${ }^{1}$, que definiu como um dos seus objetivos a compreensão acerca das propostas e práticas formativas desenvolvidas no contexto brasileiro.

O início da oferta da educação integrada entre ensino profissional e propedêutico pela Rede Federal de Educação Profissional pode ser datado de 1942, conforme análise da "Lei Orgânica do Ensino Industrial" (Decreto-Lei no 4.073/1942) $)^{2}$. No ano de 1997, sua oferta em foi impossibilitada através do

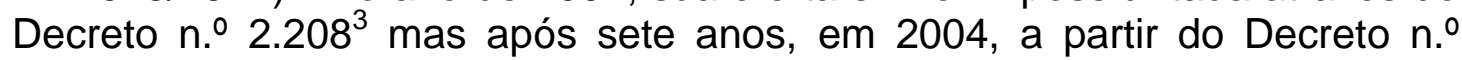
5.154 , o currículo integrado voltou a ser ofertado. O retorno da sua oferta em 2004 garantiu uma nova concepção para a proposta integrada, associando-a à concepção de "Educação Politécnica", voltada à formação omnilateral dos sujeitos.

Podemos afirmar que o atual Currículo Integrado trata-se de uma proposta formativa relativamente nova, tendo em vista as novas características adquiridas no retorno da sua oferta, e que apresenta uma proposta complexa, ainda de difícil materialização no contexto brasileiro, conforme discussões a seguir.

Neste texto, abordamos as condições de implantação e desenvolvimento da proposta integrada a partir da análise realizada por trabalhos resultantes de pesquisas empíricas em diversas instituições brasileiras. Tendo como base a pesquisa bibliográfica e documental, realizamos levantamento no Portal de Periódicos da Capes ${ }^{4}$, Plataforma SciELO ${ }^{5}$, Google Acadêmico ${ }^{6}$, além da bibliografia citada em todos os trabalhos consultados. Partimos inicialmente dos seguintes termos: "Curso Técnico Integrado ao Ensino Médio", "Curso Técnico Integrado", "Curso Integrado", “Currículo Integrado", "Formação Integrada", "Ensino Médio Integrado", "Politecnia", "Formação Politécnica".

\footnotetext{
${ }^{1}$ Pesquisa desenvolvida no Programa de Pós Graduação em Música, da Universidade Federal da Paraíba, sob a orientação do Prof. Dr. Luis Ricardo Silva Queiroz. Disponível em: < http://www.ccta.ufpb.br/ppgm/contents/documentos/teses/ITALANC.BEZERRAD2017.pdf >. Acesso em: 10/08/2018.

${ }^{2} \mathrm{O}$ documento determinou que: "Art. $5^{\circ}$ Presidirão ao ensino industrial os seguintes princípios fundamentais: [...] 3. No currículo de toda formação profissional, incluir-se-ão disciplinas de cultura geral e práticas educativas, que concorram para acentuar e elevar o valor humano do trabalhador" (BRASIL, 1942, p. 1997).

${ }^{3} \mathrm{Em}$ seu Art. $5^{\circ}$, o documento instituiu que "a educação profissional de nível técnico terá organização curricular própria e independente do ensino médio, podendo ser oferecida de forma concomitante ou seqüencial a este" (BRASIL, 1997, p. 7760).

${ }^{4}$ Disponível em: <http://www.periodicos.capes.gov.br/>.

${ }^{5}$ Disponível em: <http://www.scielo.org/php/index.php>.

${ }^{6}$ Disponível em: <https://scholar.google.com.br/>. 


\section{DESENVOLVIMENTO DA PROPOSTA INTEGRADA NO CONTEXTO EDUCACIONAL BRASILEIRO}

Destacamos inicialmente o único trabalho localizado abordando o desenvolvimento da proposta integrada num contexto diferente dos Institutos Federais de Educação, Ciência e Tecnologia - IFs. Trata-se da dissertação de mestrado elaborada por Leite (2007), desenvolvida junto ao Colégio Estadual Deputado Manoel Novaes (CEDMN), localizado na cidade de Salvador/BA, norteada a partir da seguinte questão: "qual a importância da formação musical de nível técnico na atuação profissional dos técnicos egressos do CEDMN?" (LEITE, 2007, p. 16). Apesar do foco do trabalho situar-se no período de 1993 a 1999, a autora traz importantes considerações sobre o contexto posterior de implementação do currículo integrado (2005-2006).

Acerca do processo de elaboração da proposta integrada, Leite (2007, p. 80) indicou que "a equipe pedagógica não foi capacitada para fazer essa integração, nem mesmo teve oportunidade de discutir o conceito dessa integração. Isso ficou sob a responsabilidade dos representantes das escolas que participaram dos seminários promovidos pela SEC". Apontando as dificuldades resultantes de tal processo, a pesquisadora ressaltou que os "professores [da formação geral] não compreenderam como integrar as disciplinas propedêuticas e as profissionalizantes. Alguns, inclusive, não se esforçaram muito em se informar sobre o que é o ensino médio integrado" (LEITE, 2007, p. 80). Dando a entender que o currículo integrado ainda não havia conseguido efetivamente materializar-se instituição, a pesquisadora afirmou que:

Com a possibilidade de estruturação do ensino médio integrado, o CEDMN passa novamente a oferecer o Curso Técnico de Música de nível médio, contudo, percebe-se que algumas das dificuldades enfrentadas anteriormente não foram superadas, pelo contrário, outras foram acrescentadas. Desta forma, mesmo em uma proposta de superação do dualismo estrutural da educação profissional, a conjuntura social e política do estado da Bahia corrobora com a "improdutividade" da escola, favorecendo que esta permaneça funcional à lógica do capital. (LEITE, 2007, p. 82)

Sobre o desenvolvimento da proposta integrada no contexto da Rede Federal de Educação Profissional, destacamos a dissertação de mestrado de Nessralla (2010) que realizou pesquisa de campo no Centro Federal de Educação Tecnológica de Minas Gerais (CEFET-MG), Campus Araxá. O trabalho foi realizado partindo dos seguintes questionamentos: Quais são as concepções sobre integração entre ensino médio e educação profissional nos discursos oficial, institucional, na literatura e no discurso dos sujeitos envolvidos no processo? E a partir dessas concepções e considerando-se as múltiplas variáveis que interferem no currículo, como os sujeitos efetivam, na prática, essa integração? (NESSRALLA, 2010, p. 19)

A pesquisa foi realizada abordando os professores efetivos da área de 
formação geral e da área técnica que atuavam no curso de Química durante o período de realização do trabalho. Segundo Nessralla (2010, p. 168-169), "observou-se que há diferentes concepções sobre o ensino médio integrado entre os sujeitos", tendo sido identificados docentes que "concebem o ensino médio integrado como formação integral do ser humano, em que a formação profissional é inseparável da formação geral", assim como "há outros sujeitos que consideram que o ensino médio deva ser instrumentalizado para atender o curso técnico, reduzindo o conhecimento à sua viabilidade ou utilidade" (NESSRALLA, 2010, p. 168-169).

Acerca da efetivação do processo de integração na instituição, a autora ressaltou que "a falta de formação docente adequada para se atuar no ensino médio integrado, que possibilitaria ao docente dialogar com outros campos do conhecimento, foi citada por cinco sujeitos como um fator que dificulta a integração" (NESSRALLA, 2010, p. 146). Ainda sobre as dificuldades de integração, a pesquisadora destacou que "para os sujeitos [pesquisados], a própria instituição não fomenta uma discussão mais efetiva sobre a integração curricular, não promovendo momentos para as discussões coletivas, para se conhecer o que o outro faz" (NESSRALLA, 2010, p. 142). Ainda nesse sentido, Nessralla indicou que:

\begin{abstract}
Excetuando-se os professores da parte específica [profissional] do curso, que conhecem o projeto pedagógico do curso na parte técnica, os outros docentes [da formação geral] desconhecem esses projetos. Observou-se, pelo relato dos entrevistados, que o fato de os docentes atuarem em cursos diferentes a cada ano dificulta o conhecimento do respectivo curso. Também não há interação entre os docentes da área de formação geral e da área específica. Como um sujeito não conhece o trabalho do outro, ocorre a sobreposição de conteúdos e não se observa a sequência de pré-requisitos entre as disciplinas do ensino médio e disciplinas técnico-científicas. Segundo os docentes, a instituição não possibilita momentos para troca de experiências e a própria estrutura física do prédio escolar não favorece essa interação. (NESSRALLA, 2010, p. 168)
\end{abstract}

Analisando o desenvolvimento da integração curricular em outro contexto, referente ao Curso Técnico em Agropecuária, destacamos a dissertação de Coura (2012) que "teve como objetivo central analisar e discutir em que medida os princípios da integração curricular estão presentes no IF Baiano". Para tanto, a pesquisadora abordou docentes vinculados ao Curso Técnico Integrado em Agropecuária, bem como a equipe técnicopedagógica do Campus Catu. Sobre as perspectivas docentes acerca da integração, Coura (2012, p. 108) identificou que "diante das percepções apresentadas, entendemos que existe um desconhecimento profundo do que representa a integração curricular, ainda que seja para validar o aspecto formal, ou seja, para o cumprimento da legislação, sobressaindo a visão de integração como sobreposição curricular". Reforçando este panorama, a pesquisadora destaca o posicionamento dos pedagogos quando estes afirmaram que "quanto ao maior entrave à efetivação da integração curricular 
no Campus, os Técnicos-Pedagógicos destacam a falta da visão integradora do conhecimento, por parte dos docentes, e a falta de uma melhor estruturação do curso e do currículo" (COURA, 2012, p. 123).

A pesquisadora ressalta ainda que "dos 16 envolvidos nesse estudo, apenas $37,5 \%$ afirmaram ter participado de alguma formação sobre a integração nos cursos do Ensino Profissional" (COURA, 2012, p. 111). Caracterizando uma visão restrita e hierarquizadora da integração entre conhecimentos da formação geral e da formação técnica presente na instituição, Coura (2012) destacou:

Em relação à importância dos componentes disciplinares do núcleo geral do currículo para a formação do técnico, todos os docentes concordam que são importantes. Entretanto, quando solicitados a justificar a importância desses conteúdos, grande parte deles ainda enxerga os componentes disciplinares do núcleo geral, como suporte aos componentes disciplinares do núcleo profissional. (COURA, 2012, p. 112)

Após realizar análise sobre o Projeto Pedagógico Curricular do Curso de Agropecuária, a pesquisadora teceu a seguinte reflexão:

Em relação ao PPC, foi possível constatar que este documento não orienta no sentido da integração curricular, conforme afirmado pelos próprios docentes durante a pesquisa empírica, pois não sinaliza nenhuma proposta integradora do conhecimento, ao contrário disso, omite-se em relação à integração entre as diversas áreas do conhecimento, principalmente sobre as questões metodológicas para esse fim. (COURA, 2012, p. 129)

Confirmando o distanciamento do PPC em relação à atual proposta integrada, a autora faz a seguinte análise do perfil do egresso contida no documento:

[...] percebemos no perfil do egresso, mais uma vez, uma concepção de formação fundamentada nos princípios do toyotismo, que valoriza elementos como a participação, criatividade na busca de soluções para aumentar a produtividade, com qualidade, e estímulo ao empreendedorismo. (COURA, 2012, p. 120)

Por fim, a pesquisadora chegou à conclusão que "da forma como entendemos a integração curricular, ela não se manifesta no curso estudado, fato evidenciado, principalmente, pela falta do entendimento dos docentes sobre uma concepção de ensino integrado" (COURA, 2012, p. 128, grifos nossos). Desse modo, conforme Coura (2012),

Percebemos que existem elementos da integração curricular que estão presentes na prática pedagógica dos educadores, sujeitos desta pesquisa, mas não ainda com a perspectiva de integrar trabalho, ciência e cultura, e muito menos, com a proposta de uma educação politécnica e da formação omnilateral. (COURA, 2012, p. 128) 
Outro trabalho que realiza análise do desenvolvimento do Currículo Integrado refere-se à pesquisa de doutorado realizada por Pontes (2012) cujo objetivo geral foi definido nos seguintes termos: "analisar como o Ensino Médio Integrado tem se constituído em seus aspectos institucionais, organizacionais e político-pedagógicos e para qual perspectiva de formação ele sinaliza no IFPB/Campus João Pessoa" (PONTES, 2012, p. 18-19). Com essa finalidade, além da análise de documentos, a pesquisadora abordou 40 docentes e três pedagogas do referido Campus. Acerca do contexto institucional no qual houve o retorno da educação profissional ofertada na forma integrada, Pontes (2012, p. 157) destacou que "com a edição do Decreto $n^{\circ}$ 5.154/2004 ${ }^{7}$, [no campus João Pessoa,] não houve muita clareza do que este marco legal representava em relação ao Decreto [no 2.208/1997] que o antecedeu". A pesquisadora conclui seu raciocínio afirmando que,

\begin{abstract}
$\mathrm{Na}$ ocasião, prevaleceu o entendimento de que seria interessante para a Instituição "voltar" a oferecer os cursos técnicos integrados de outrora, o que se refletiu nos debates seguintes, resultando na aceitação da proposta do currículo integrado por três coordenações, inicialmente: Edificações, Eletrotécnica e Mecânica. A aceitação da proposta na Instituição se deu em meio ao desconhecimento dos fundamentos do que viria a ser denominado Ensino Médio Integrado. (PONTES, 2012, p. 157, grifos nossos)
\end{abstract}

Refletindo acerca da falta de apropriação institucional sobre os fundamentos que caracterizam a proposta integrada, a pesquisadora teceu 0 seguinte o comentário:

Haveria que se discutir de forma fundamentada as implicações político-ideológicas, epistemológicas, filosóficas e sociais de uma proposta de integração que, nos moldes defendidos pelos estudiosos da área Trabalho e Educação, avançaram no sentido da defesa de um Ensino Médio Integrado assumido como projeto de travessia para uma educação politécnica e de emancipação política, social e econômica. Tal nível de complexidade e de aspectos não foram tratados nas discussões encampadas na Instituição. (PONTES, 2012, p. 159-160)

Caracterizando a referida ausência de discussões acerca da proposta do currículo integrado no Campus João Pessoa, Pontes (2012, p. 185) apontou que "o processo de elaboração dos projetos pedagógicos dos cursos integrados se deu em tempo insuficiente para garantir o aprofundamento das discussões acerca dos fundamentos da proposta de EMI [Ensino Médio Integrado]". Como consequência desse processo realizado de forma "aligeirada", a pesquisadora destaca que "o EMI do IFPB/Campus João Pessoa contemplou em seu projeto político-pedagógico fundamentos e princípios alinhados com a educação politécnica, mas desconhecidos ou não

\footnotetext{
${ }^{7}$ O decreto no 5.154 de 23 de julho de 2004, revogando o Decreto ํㅜ 2.208, de 17 de abril de 1997, possibilitou o retorno da oferta da educação profissional em sua forma integrada ao Ensino Médio.

Vol. 1 (2020)
} 
suficientemente apropriados pela expressiva maioria de professores" (PONTES, 2012, p. 232). Ainda nesse sentido, a pesquisadora reflete que:

Não obstante o marco teórico dos projetos analisados contemple alguns princípios da educação politécnica, isto não significa que tal perspectiva tenha sido assumida pelos docentes da Instituição. Ademais, em alguns trechos dos projetos encontramos referências que se conflitam com os ideais da politecnia, e nos discursos de professores, identificamos concepções que, por vezes, se conflitam com esta fundamentação teórica apresentada como balizadora dos cursos integrados. Ou mesmo, eles demonstram desconhecer ou não se interessar por tais discussões de cunho filosófico e político-ideológico, mas, apenas, com questões de natureza pedagógica eminentemente instrumental. (PONTES, 2012, p. 170, grifos nossos)

Analisando o contexto de implantação do currículo integrado, faz-se importante ressaltar que tal processo ocorreu em simultaneidade à transformação dos então Centros Federais de Educação Tecnológica (CEFETs) em Institutos Federais de Educação, Ciência e Tecnologia (IFs), bem como o processo de significativa expansão da Rede Federal de Educação Profissional e Tecnológica. Refletindo sobre esse contexto, Pontes (2012) argumenta que:

Um dos elementos que mais comprometeram o desenvolvimento do EMI no Instituto foi o desconhecimento da proposta em seus aspectos político-ideológicos, filosóficos e pedagógico-curricular, aliado à falta de investimento na formação e no apoio técnico-pedagógico aos professores. Tais situações contribuíram para 0 desenvolvimento de uma prática docente em desacordo com os princípios defendidos nos projetos. A falta de investimento na formação docente e o insuficiente apoio técnicopedagógico pelo Setor Pedagógico foram agravados a partir de 2009, momento em que a Instituição passou à condição de IFPB e priorizou o desenvolvimento de ações relativas às novas exigências postas pela necessidade de consolidação da nova institucionalidade e sua expansão. (PONTES, 2012, p. 188, grifos nossos)

Corroborando com o acima exposto, a pesquisadora destacou que, para os docentes das diversas áreas da instituição, o processo de "ifetização", assim como o grande processo de expansão pelo qual vem passando a Rede na última década", "interferiram no desenvolvimento da

\footnotetext{
${ }^{8}$ Conforme indica o portal do Ministério da Educação, "a Rede Federal está vivenciando a maior expansão de sua história. De 1909 a 2002, foram construídas 140 escolas técnicas no país. Entre 2003 e 2016, o Ministério da Educação concretizou a construção de mais de 500 novas unidades referentes ao plano de expansão da educação profissional, totalizando 644 campi em funcionamento. Disponível em: <http://redefederal.mec.gov.br/expansao-da-redefederal>. Acesso em: 20/04/2017.
} 
proposta do EMI resultando na pouca atenção dada ao acompanhamento e avaliação dos cursos, bem como à retomada de estudos, planejamentos e discussões pedagógicas sobre a proposta e seus fundamentos" (PONTES, 2012, p. 173). Segundo a autora, "nesse contexto atribulado de mudanças impostas pela nova institucionalidade, alguns professores apontaram que ainda não haviam nem sedimentado as mudanças como CEFET e já foram envolvidos na ifetização" (PONTES, 2012, p. 175). Desse modo,

\begin{abstract}
Em sua vivência, a proposta do EMI se restringiu a mudanças na organização da matriz curricular, concebida em termos estreitos de ajustes de cargas horárias e direcionamentos das disciplinas de Formação Geral para a profissionalização, que não lograram êxito. Outras perspectivas anunciadas de natureza metodológica (desenvolvimento de projeto integrador, visitas técnicas) também não se efetivaram na prática. (PONTES, 2012, p. 237, grifos nossos)
\end{abstract}

Concluindo seu estudo, e caracterizando os limitados processos de “integração" identificados no Campus João Pessoa, Pontes (2012) destacou a falta de coesão institucional em torno da proposta integrada, de modo que foram localizadas apenas iniciativas integradoras desenvolvidas individualmente por parte de alguns docentes, muitas vezes distantes de uma concepção integral de formação humana. Caracterizando tais práticas, a autora afirmou que:

Em que pese tenhamos identificado alguns professores que desenvolviam atividades didáticas integradoras aparentemente próximas de uma perspectiva de integração curricular, dado seu caráter isolado e pontual, o alcance interdisciplinar era limitado. A perspectiva da integração de tais iniciativas é questionável, pois o fato de elas se desenvolverem com algum nível de interdisciplinaridade, não implica que tivessem como horizonte a formação integral do sujeito humano. Como discutimos, a maioria das ações desenvolvidas se voltaram para fins de contextualização e problematização de situações de trabalho, descoladas de uma abordagem crítica e reflexiva que avançasse para além da perspectiva de integração à vida produtiva. (PONTES, 2012, p. 231, grifos nossos)

Aprofundando a realidade de instituições que ofertam a Educação Técnica de Nível Médio na forma Integrada, destacamos ainda o trabalho de mestrado desenvolvido por Leite (2014), também realizado no Instituto Federal de Educação, Ciência e Tecnologia da Paraíba - IFPB, Campus João Pessoa. A pesquisa foi realizada com a participação de 21 docentes e teve como objetivo geral:

[...] analisar alguns sentidos da política de currículo da Educação Profissional Técnica Integrada ao Ensino Médio (EPTIEM), verificando, através dos discursos dos docentes e dos documentos oficiais nacionais e locais, as implicações desses sentidos na prática docente da Educação Profissional 
Técnica Integrada ao Ensino Médio do IFPB - Campus João Pessoa. (LEITE, 2014, p. 19)

Após a realização de entrevistas e aplicação de questionários, Leite (2014, p. 66) ressaltou que "em cada discurso, o currículo integrado é entendido de forma diferente". Caracterizando este contexto marcado pela ausência de efetiva compreensão acerca da concepção integrada de educação, entendida via de regra apenas como "interdisciplinar", a pesquisadora ressaltou que:

Nossa vivência no cotidiano dessa instituição e os discursos
sobre o currículo para essa modalidade de educação nos
fizeram perceber que os sentidos de currículo emergiam de
forma unidirecional, ou seja, falta um entendimento maior
da política que vá além da preocupação com o aspecto
simplesmente metodológico do processo de integração
curricular [...] (LEITE, 2014, p. 93, grifos nossos)

Ainda nesse sentido, Leite (2014, p. 90) comenta que "há uma busca contínua do processo de integração curricular, com ênfase no processo metodológico, em detrimento dos demais princípios dessa política". Exemplificando a reflexão acima disposta, ressaltamos a fala de um dos docentes abordados na pesquisa de Leite (2014), seguida da análise da pesquisadora acerca do comentário:

"Deveria no caso haver essa integração, mas na prática não ocorre" (DOCENTE 06). Para nós, esse discurso é indicativo de uma compreensão que agrega sentidos meramente de aspecto metodológico, uma vez que restringe o sentido da integração curricular à junção das duas grandes áreas - a da formação geral e a da formação profissional. (LEITE, 2014, p. 120)

Realizando análise dos Projetos Pedagógicos Curriculares (PPCs) dos cursos pesquisados, Leite (2014) aponta a ausência de reflexões e críticas acerca de determinadas instruções advindas verticalmente do Ministério da Educação que não se adequam à realidade institucional, não contribuindo portanto para o desenvolvimento da formação ofertada. Nesse sentido, refletindo acerca da excessiva subordinação dos PPCs analisados ao Catálogo Nacional dos Cursos Técnicos ${ }^{9}$, a autora tece 0 seguinte comentário:

$\mathrm{Na}$ análise dos planos pedagógico dos Cursos de Educação Profissional Técnica Integrada ao Ensino Médio, observa-se um direcionamento, em alguns momentos, linear, em relação à 'imposição' das nomenclaturas e dos perfis profissionais, articulados por meio do Catálogo Nacional dos Cursos Técnicos para o Ensino Médio, percebido pelos envolvidos na organização curricular do IFPB, Campus João

\footnotetext{
${ }^{9}$ O Catálogo Nacional de Cursos Técnicos - CNCT é um instrumento criado pelo MEC para padronizar a oferta de cursos técnicos de nível médio, padronizando as denominações e os perfis que devem ser por eles desenvolvidos. Atualmente o CNCT classifica os cursos técnicos de nível médio em treze eixos tecnológicos.
} 
Pessoa, como um conjunto de competências das quais não se permite fugir. Isso significa que o MEC 'impõe' o cumprimento do que está determinado e justifica que é preciso padronizar e racionalizar os conhecimentos técnicos e o IFPB, Campus João Pessoa - tem aceitado. Essa imposição de sentido não vem sendo criticada nem questionada pelos que articulam essa modalidade de educação. (LEITE, 2014, p. 82, grifos nossos)

Ainda na perspectiva da subordinação institucional à mecanismos que vão de encontro à proposta integrada, Leite (2014, p. 120) comenta "que esse currículo contempla demandas amplas, que se vinculam aos interesses internacionais através do BID [Banco Interamericano de Desenvolvimento], do Banco Mundial, do BIRD [Banco Internacional para Reconstrução e Desenvolvimento], da OCDE [Organização para a Cooperação e o Desenvolvimento Econômico], etc., que impõem exigências ao mundo produtivo nacional e local". Sendo necessário destacar que se tratam de órgãos que historicamente impuseram reformas curriculares visando atender prioritariamente às demandas do mercado de trabalho, desvinculadas de propostas voltadas à formação humana integral dos estudantes.

Outra questão problemática identificada junto aos projetos analisados, conforme analisa Leite (2014), diz respeito ao excesso de componentes curriculares (disciplinas) presentes nas matrizes dos cursos:

Isso faz com que essas matrizes se tornem muito extensas e, ao mesmo tempo, sobrecarreguem os docentes em suas atividades em sala de aula, além de provocar uma sobrecarga de atividades para os estudantes que, nem sempre, conseguem dar conta da complexidade imputada aos oriundos das posições sociais desfavorecidas historicamente, que terminam sendo excluídos dos diferentes projetos de sociedade apontados pela presente pesquisa. (LEITE, 2014, p. 103, grifos nossos)

Conforme fragmento acima destacado, a autora ressalta além do aspecto quantitativo referente às extensas matrizes curriculares, a complexidade dos conteúdos trabalhados e a consequente dificuldade imputada aos estudantes advindos das classes sociais mais baixas, via de regra, egressos do sistema público de ensino dos municípios. A evasão dessa parcela de estudantes no Campus João Pessoa já foi destacada por autores como Queiroga (2006) e Carneiro (2015).

Caracterizando, de forma resumida, o panorama encontrado na instituição acerca da proposta de educação integrada, apresentamos a seguinte consideração de Leite (2014):

Assim, o processo de articulação dessa política curricular parece mais reduzido aos aspectos metodológicos em detrimento das possibilidades de articulação em favor da mudança social, o que sinaliza para um entendimento desse processo educativo aproximado da impossível neutralidade política. A impressão que causa é de que, para a maioria 


\begin{abstract}
dos docentes, integração curricular e interdisciplinaridade parecem ser pensadas quase que como sinônimos, excluindo-se, de forma geral, o sentido da relação desse significante com a possibilidade de mudança nas relações de opressão/subordinação presentes na dinâmica social. (LEITE, 2014, p. 183, grifos nossos)
\end{abstract}

A fala de Leite (2014) ressalta uma questão recorrente nos contextos de oferta do currículo integrado: a compreensão reducionista desse currículo como simplesmente um "currículo interdisciplinar". Apesar da importância da interdisciplinaridade nesse contexto, é necessário explicitar que ela configura "apenas" um dos elementos que caracterizam a proposta integrada, visto que a "integração curricular" necessita estar voltada à extinção da histórica dualidade educacional brasileira, integrando conhecimentos práticos e teóricos, objetivando a formação omnilateral dos indivíduos.

Ainda refletindo sobre o desenvolvimento da proposta integrada no cenário brasileiro, apontamos a pesquisa de mestrado desenvolvida por Estivalete (2014) que foi norteada pelo seguinte questionamento: "como o currículo integrado poderia colaborar para a formação básica e profissional no Curso Técnico Integrado de Nível Médio em Agropecuária, no Instituto Federal Catarinense - Campus Rio do Sul?". Valendo-se da observação participante e entrevista semiestruturada, o pesquisador abordou seis professores, dois técnicos da equipe pedagógica e seis estudantes do Curso Integrado em Agropecuária. Acerca da aproximação dos docentes com o PPC do Curso, Estivalete (2014) apontou que, "embora já tendo ouvido falar e conhecendo a ementa do componente curricular o qual leciona, mais de $70 \%$ deles não sabem sobre as outras informações que compõem o documento, em especial, os mais novos (efetivos ou substitutos), que não participaram da sua construção, em 2010" (ESTIVALETE, 2014, p. 77). Sobre a falta de apropriação por parte dos professores do conteúdo dos documentos institucionais, o pesquisador mencionou que "não há incentivo por parte da Instituição para que os professores conheçam os documentos institucionais como o PDI, o PPI e o PPC, pois o número de reuniões gerais destinadas à formação pedagógica com professores é muito reduzido, tendo, no ano de 2013, apenas 3 momentos" (ESTIVALETE, 2014, p. 77-78). Diante desse contexto, o autor argumenta que:

[...] chegamos à conclusão que, embora o Decreto 5154 tenha sido aprovado em 2004, regulamentando a integração entre o Ensino Básico e a Educação Profissional Técnica de Nível Médio, sua repercussão na prática ainda é muito tímida, pois não alcançou ainda a superação das diferenças entre as duas modalidades de ensino. (ESTIVALETE, 2014, p. 101, grifos nossos)

Destacando outro aspecto que se apresentou como recorrente nos contextos pesquisados do Currículo Integrado, Estivalete (2014) faz menção ao excesso de componentes curriculares e a consequente sobrecarga de atividades que caracterizam a rotina dos estudantes e docentes da instituição: 
Dessa forma, o volume de aulas e de trabalhos, bem como a quantidade de componentes curriculares se avoluma com jornadas compostas por $\mathbf{8}$ horas diárias de aulas, estudos de dependência, atividades de Iniciação Científica com revisão bibliográfica ou experimentos, além de outras atividades complementares de formação e possíveis tarefas oriundas das aulas assistidas. Tudo isso se desdobra numa maratona diária, tendo como consequência a falta de um tempo livre para estudos individuais que, sabidamente, consolida as aprendizagens feitas em sala de aula ou em práticas em âmbito coletivo junto com o professor. (ESTIVALETE, 2014, p. 107, grifos nossos)

Buscando sintetizar o panorama encontrado no Curso Integrado de Agropecuária do Instituto Federal Catarinense, Campus Rio do Sul, destacamos as seguintes palavras do pesquisador:

\begin{abstract}
A partir da observação, nas reuniões de professores, alguns pontos sensíveis foram registrados quando o grupo refletia sobre o engessamento da proposta, entre eles, destacam-se: falta de consistência das políticas públicas com relação aos estímulos necessários para a integração curricular, levando em conta as especificidades de um curso técnico de nível médio, isto é, não basta somente mudar o nome do curso, os professores não conhecem o curso, seu ementário e seus ambientes de aprendizagem, em especial as UEP's [Unidades de Ensino e Produção] e o que se desenvolve nelas; falta formação pedagógica continuada como política institucional; não há estímulo para participação das reuniões, nem a valorização dos professores através da presença dos gestores como mediadores nas reuniões; fraca atuação pedagógica face à desarticulação do Núcleo Pedagógico; o elevado número de componentes curriculares também é um agravante para a implementação de uma proposta curricular integrada. (ESTIVALETE, 2014, p. 105-106)
\end{abstract}

Por fim, destacamos a pesquisa empreendida por Araújo et al. (2012) cujo objetivo buscou "investigar as contribuições da disciplina História no ensino técnico integrado de nível médio do Instituto Federal de Ciência e Tecnologia de Goiás - IFG, para a formação do técnico de Edificações”. Após a análise dos questionários respondidos pelos estudantes do $3^{\circ}$ ano do curso, os pesquisadores apontam para uma significativa desarticulação entre os componentes curriculares, chegando à seguinte conclusão:

Da análise das respostas dos alunos pode-se apreender que, apesar de valorizarem a História na sua formação pessoal, a maioria deles não percebe a importância da disciplina na sua vida profissional. Além disso, não compreendem seu papel na vida acadêmica, o que pode ser decorrência da falta de articulação entre as disciplinas de formação geral e as de formação técnica, evidenciada nas falas dos professores [...] (ARAÚJO et al., 2012, p. 17, grifos nossos) 
Desse modo, os trabalhos localizados que investigaram o processo de implantação e desenvolvimento da proposta de formação integrada, em cursos das diversas áreas, vivenciados em instituições de diversos estados do país, portanto com distintas realidades, não apontaram experiências realizadas com efetivo êxito. É necessário enfatizar que não foram encontradas experiências bem sucedidas nem no sentido mais restrito que a integração pode adotar (numa perspectiva exclusivamente interdisciplinar entre as disciplinas do currículo), tampouco no sentido amplo (ideal) que engloba ainda o sentido omnilateral (integral) da formação, voltado à emancipação dos seres humanos.

\section{CONSIDERAÇÕES FINAIS}

O contexto que caracteriza a realidade das instituições educacionais públicas do Brasil, incluindo aquelas pertencentes à Rede Federal de Educação Profissional e Tecnológica, pode ser caracterizado como permeado por distintas correlações de forças políticas (reflexo das disputas encontradas nas instâncias sociais, políticas e econômicas) que em alguns momentos apontam para a materialização (ou, pelo menos, tentativa) de propostas voltadas à formação humana dos sujeitos, como o Currículo Integrado, mas em outras situações aponta para propostas completamente antagônicas, esvaziadas do sentido de formação integral/omnilateral, como a do Programa Nacional de Acesso ao Ensino Técnico e Emprego - PRONATEC que declaradamente tem como objetivo garantir mão-de-obra "qualificada" e barata para o desenvolvimento do País a partir de uma "inclusão social" das camadas mais pobres da população ${ }^{10}$.

Partindo desse cenário político, evidencia-se a dificuldade que uma proposta educacional cujo objetivo não corresponde diretamente aos interesses restritos do mercado de trabalho, como a proposta do currículo integrado, tende a encontrar para conseguir uma adequada materialização. Destaca-se ainda a "vocação institucional" das instituições vinculadas à Rede Federal de Educação Profissional que, apontando para a oferta de uma educação historicamente vinculada a correntes educacionais como a "tecnicista", distanciou-se da oferta de uma formação humana em seu sentido mais amplo. Compreendemos então que para que a proposta integrada, de fato, venha a lograr êxito nas Instituições Técnico-Profissionais brasileiras, demanda-se, a médio e longo prazo, um significativo esforço de ordem institucional para a implantação de políticas que adquiram caráter permanente e sobrevivam às transitórias gestões educacionais e governamentais.

\footnotetext{
${ }^{10}$ Para um maior aprofundamento acerca das políticas e propostas do Pronatec, consultar Carneiro (2018). 


\section{REFERÊNCIAS}

ARAÚJO, Denise Silva et al. O ensino de história no currículo integrado do curso de Edificações do IFG: o olhar dos professores e dos alunos. In: SEMINÁRIO NACIONAL DE EDUCAÇÃO PROFISSIONAL E TECNOLÓGICA, 3., Belo Horizonte, 2012. Anais... Belo Horizonte: CEFETMG, 2012. Disponível em:

<http://www.senept.cefetmg.br/galerias/Anais_2012/GT-01/GT01-004.pdf>. Acesso em: 22/09/2018.

BRASIL. Leis, Decretos. Decreto-Lei no 4.073, de 30 de Janeiro de 1942. Lei orgânica do ensino industrial. In: Diário Oficial da União - Seção 1 9/2/1942, p. 1997 (Publicação Original). 1942. Disponível em: <https://www.planalto.gov.br/ccivil_03/decreto-lei/1937-1946/Del4073.htm>. Acesso em: 08/09/2018. . Leis, Decretos. Decreto no 2.208, de 17 de Abril de 1997. Regulamenta o § 20 do art. 36 e os arts. 39 a 42 da Lei ํo 9.394 , de 20 de dezembro de 1996, que estabelece as diretrizes e bases da educação nacional. In: Diário Oficial da União - Seção 1 - 18/4/1997, p. 7760 (Publicação Original). 1997. Disponível em: <http://www2.camara.leg.br/legin/fed/decret/1997/decreto-2208-17-abril-1997445067-publicacaooriginal-1-pe.html>. Acesso em: 07/06/2018. . Leis, Decretos. Decreto no 5.154, de 23 de Julho de 2004. Regulamenta o § 20 do art. 36 e os arts. 39 a 41 da Lei ํo 9.394, de 20 de dezembro de 1996, que estabelece as diretrizes e bases da educação nacional, e dá outras providências. In: Diário Oficial da União - Seção 1 26/7/2004, p. 18 (Publicação Original). 2004. Disponível em: <http://www2.camara.leg.br/legin/fed/decret/2004/decreto-5154-23-julho2004-533121-publicacaooriginal-16200-pe.html>. Acesso em: 02/11/2018.

CARNEIRO, Italan. Implantação do Programa Nacional de Acesso ao Ensino Técnico e Emprego (Pronatec): inclusão excludente. Revista Eixo, Brasília/DF, v. 8, n. 3, p. 81-87, jul./dez 2018. Disponível em: <http://revistaeixo.ifb.edu.br/index.php/RevistaEixo/article/view/638/356>. Acesso em: 02/01/2019. . Perfil socioeconômico discente: reflexões acerca das condições materiais dos estudantes do Curso Técnico em Instrumento Musical do IFPB, campus João Pessoa. In: CONGRESSO NACIONAL DA ASSOCIAÇÃO BRASILEIRA DE EDUCAÇÃO MUSICAL (ABEM), 22., 2015, Natal/RN.

Anais... Natal/RN: UFRN, 2015. Disponível em: <https://www.academia.edu/28752084/Perfil_socioecon\%C3\%B4mico_discen te_reflex\%C3\%B5es_acerca_das_condi\%C3\%A7\%C3\%B5es_materiais_dos _estudantes_do_Curso_T\%C3\%A9 cnico_em_Instrumento_Musical_do_IFPB _campus_Jo\%C3\%A3o_Pessoa>. Acesso em: 10/01/2019. 
COURA, Helena Luiza Oliveira. A possível integração curricular no Instituto Federal de Educação, Ciência e Tecnologia Baiano: análise do Curso Técnico em Agropecuária. 2012. 161f. Dissertação (Mestrado em Educação), Programa de Pós-Graduação em Educação, Universidade Federal da Bahia, Salvador, 2012. Disponível em: <https://repositorio.ufba.br/ri/bitstream/ri/9268/1/555555llp.pdf>. Acesso em: $11 / 06 / 2018$.

ESTIVALETE, Emerson Bianchini. Currículo Integrado: uma reflexão entre o legal e o real. 2014. 122f. Dissertação (Mestrado em Educação), Programa de Pós-Graduação em Educação, Pontifícia Universidade Católica do Rio Grande do Sul, Porto Alegre, 2014. Disponível em: <http://repositorio.pucrs.br/dspace/bitstream/10923/5774/1/000457206Texto\%2BCompleto-0.pdf>. Acesso em: 20/03/2018.

LEITE, Jaqueline Câmara. O Curso Técnico de Música do Colégio Estadual Deputado Manoel Novaes na atuação profissional de seus egressos: uma abordagem sociohistórica. 2007. 176f. Dissertação (Mestrado em Música), Programa de Pós-Graduação em Música, Universidade Federal da Bahia, Salvador, 2007. Disponível em:

<http://www.repositorio.ufba.br:8080/ri/bitstream/ri/9168/1/Dissertacao\%2520J aqueline\%2520Leite\%2520seg.pdf >. Acesso em: 12/05/2018.

LEITE, Jocileide Bidô Carvalho. Sentidos da política de currículo da Educação Profissional Técnica Integrada ao Ensino Médio do IFPB Campus João Pessoa. 2014. 203f. Dissertação (Mestrado em Educação), Programa de Pós-Graduação em Educação, Universidade Federal da Paraíba, João Pessoa, 2014. Disponível em:

<http://bdtd.biblioteca.ufpb.br/tde_arquivos/12/TDE-2014-08-29T113500Z3058/Publico/arquivototal.pdf>. Acesso em: 22/07/2018.

NESSRALLA, Marília Ramalho Domingues. Currículo integrado do ensino médio com a educação profissional e tecnológica: da utopia à concretização do currículo possível. 2010. 208 f. Dissertação (Mestrado em Educação Tecnológica). Programa de Pós-Graduação em Educação Tecnológica, Centro Federal de Educação Tecnológica de Minas Gerais, 2010. Disponível em:

$<$ http://educacaoprofissionalbrasil.files.wordpress.com/2012/05/currc3adculointegrado-do-ensino-mc3a9dio.pdf>. Acesso em: 10/03/2018.

PONTES, Ana Paula Furtado Soares. Ensino Médio Integrado: formação politécnica como horizonte?. 2012. 256f. Tese (Doutorado em Educação), Programa de Pós-Graduação em Educação, Universidade Federal de Pernambuco, Recife, 2012. Disponível em:

<http://repositorio.ufpe.br/bitstream/handle/123456789/12990/ANAPAULAcon cluido.pdf? sequence=1\&isAllowed=y >. Acesso em: 25/03/2018.

QUEIROGA, Ana Lúcia Ferreira de. A pedagogia das competências nos ursos técnicos do CEFET-PB: limites e contradições. 2006. 128f. Dissertação (Mestrado em Educação), Programa de Pós-graduação em Educação, 
Universidade Federal da Paraíba, João Pessoa, 2006. Disponível em:

<http://www.ce.ufpb.br/ppge/Dissertacoes/dissert06/Ana\%20Lucia\%20Ferreir a/A\%20PEDAGOGIA\%20DAS\%20COMPET\%CANCIAS\%20NOS\%20CURS OS\%20T\%C9C..pdf>. Acesso em: 18/11/2018. 